\title{
Toward cultural competence in cancer genetic counseling and genetics education: Lessons learned from Chinese-Australians
}

Kristine Barlow-Stewart, PhD, FHGSA ${ }^{1}$, Soo See Yeo, BSc(Hons), $\mathrm{MSc}^{2}$, Bettina Meiser, BAHons, PhD ${ }^{3,4}$, David Goldstein, MMBS, FRACP $P^{3,5}$, Kathy Tucker, MBBS, FRACP $P^{3,5}$, and Maurice Eisenbruch, MD, FRANZCP

\begin{abstract}
Purpose: In societies such as Australia with a strong multicultural makeup, culturally determined attitudes to genetics, testing, and counseling may be incompatible with current genetics service provision. Methods: An ethnographic investigation using purposive sampling to increase subject diversity was used to explore the range of beliefs about kinship and inheritance using Chinese-Australians as a case. Participants comprised a sample of 15 Chinese-Australians who had been recruited through several community-based organizations. Results: The level of acculturation does not correlate with holding beliefs about inheritance, kinship, and causes of hereditary cancer that are based on "Western" biomedical or traditional concepts. Mismatch between beliefs may exist within families that can impact participation in cancer genetic testing. Family history taking that underpins the surveillance, management, and referral to genetic counseling where there is a strong family history of breast, ovarian, or colorectal cancer can also be impacted unless recognition is made of the patrilineal concept of kinship prevalent in this Chinese-Australian community. Conclusion: This community-based study confirmed and validated views and beliefs on inheritance and kinship and inherited cancer attributed to senior family members by Chinese-Australians who attended cancer genetic counseling. Barriers to communication can occur where there may be incompatibility within the family between "Western" and traditional beliefs. The findings were used to develop strategies for culturally competent cancer genetic counseling with Australian-Chinese patients. These include nonjudgmental incorporation of their belief systems into the genetic counseling process and avoidance of stereotyping. They have also influenced the development of genetics education materials to optimize family history taking. Genet Med
\end{abstract} 2006:8(1):24-32.

Key Words: kinship, Chinese culture, family history, cultural competence, cancer genetics, genetic counseling, genetics education

Many anecdotal reports and published studies of uptake of genetic testing and genetic counseling in Australia and other English-speaking countries indicate a preponderance of people attending genetics clinics who are from an Anglo-Celtic background with a relative underrepresentation from linguistically and culturally diverse backgrounds. For example, a cross-sectional study of intake over a 4 -week period among 22 regional cancer genetics services in the United Kingdom found that only $3 \%$ of referrals were individuals from ethnic minorities. ${ }^{1}$ Given the high prevalence of $B R C A 1 / 2$ and hered-

\footnotetext{
From the ${ }^{I}$ The Center for Genetics Education, Royal North Shore Hospital, St. Leonards, Australia; ${ }^{2}$ Center for Culture and Health, University of New South Wales, Australia; ${ }^{3}$ Department of Medical Oncology, Prince of Wales Hospital, Randwick, Australia; ${ }^{4}$ School of Psychiatry, University of NSW, Australia; ${ }^{5}$ Prince of Wales Clinical School, University of NSW, Australia; ${ }^{6}$ Institute for Health and Diversity, Victoria University, Australia.

Kristine Barlow-Stewart, PhD, FHGSA, Director, The Centre for Genetics Education Building 36, Royal North Shore Hospital, St. Leonards, NSW 2065 Australia.

Received: June 15, 2005.

Accepted: October 31, 2005.
}

DOI: 10.1097/01.gim.0000195884.86201.a0 itary nonpolyposis colorectal cancer-related mutations found in several ethnic groups (e.g., Risch et al. ${ }^{2}$ ), it seems that genetic counseling for risk of breast, ovarian, or colorectal cancer is relevant to all people, not just those from the dominant culture, and that cultural competence in familial cancer services is needed to ensure equity and overcome barriers based on ethnicity.

Cultural competence means that services and service providers are attuned to the impact of culture-not only that of the patient but their own - on delivery of the service to enable support and health education that makes sense to people no matter what their cultural backgrounds. ${ }^{3}$ Despite the burgeoning interest in cultural competence for health services, there are still many challenges to overcome in the development and maintenance of culturally competent genetic counseling services. ${ }^{4,5}$ Culturally competent genetic counseling services and practice embraces the role of culture in shaping the attitudes, values, behaviors, and practices of both counselor and counselee and their wider family, at systemic, organizational program, and individual levels. ${ }^{4-7}$ Although many factors 
likely contribute to underuse of cancer genetics services, cultural beliefs in particular are a key barrier to access and optimal service provision. ${ }^{8}$ Individuals may find it hard to reconcile the cultural emphasis on family reputation, privacy, and culturebased strategies of solving problems with consulting a genetic counselor. ${ }^{8,9}$ Understanding these barriers is key to the development of culturally competent services.

Where there is a strong family history of breast, ovarian, or colorectal cancer, existing guidelines on surveillance, management, and referral to genetic counseling depend on triaging using family histories developed from Anglo-Celtic ideas in which inheritance reflects kinship coming equally from mother and father (bilateral kinship). ${ }^{10-14}$ A correct interpretation of the family history of a range of cancers underpins risk assessment and appropriate use of genetic testing. ${ }^{10,15}$ Many cultures, however, have a profoundly different understanding of kinship that is likely to impact presentation of family history and therefore appropriate referral to cancer genetics services.

A number of studies using quantitative methodologies have been conducted into culture and hereditary cancer focusing on Afro- and Hispano-Americans (see Meiser et al. for a summary ${ }^{8}$ ). We recently proposed that further research was indicated to build on and extend these studies. ${ }^{8}$ An increased focus on various Asian societies seemed warranted, given their particular notions of kinship and patrilineal descent systems, to explore the clinical relevance of links between folk notions of inheritance and kinship. ${ }^{8}$ We suggested that research into cultural aspects of cancer genetics would be enhanced if replicated in other multicultural settings using qualitative methodologies. ${ }^{8}$

To provide a basis for the development of cultural competence and focusing on an Asian society within Australia, we subsequently undertook an ethnographic study with participant observation among families with hereditary cancer attending familial cancer services. ${ }^{16}$ Most of the informants had high acculturation and held beliefs with biomedical explanations about hereditary cancer. Yet they also acknowledged the powerful influence of traditional Chinese beliefs held by themselves and/or their senior relatives. Here "inheritance" and "genetics" reflected Buddhist views of retribution in this life for wrong-doings committed in a previous life. ${ }^{16}$ An example of this includes having offended the ancestors. ${ }^{16}$ The extensive mismatch of attributes and beliefs identified between those who attended the clinic and reportedly held by their senior family members created barriers to optimal service use. ${ }^{16}$ Traditional patterns of beliefs that were described include that father and mother contributed to the child's makeup, but these were explained in terms of the ying-yang theory; the dominance of life force (yang chi) and the shaping of genes transmitted through the paternal line; and natural and supernatural forces operating in the cause of hereditary cancer. ${ }^{16}$

Because the sample in this previous work had fairly high educational and acculturation levels, it was important to more fully capture the diversity of views about inheritance and kinship related to hereditary cancer. ${ }^{16}$ In the next phase of our research, we therefore undertook the community-based study described here to validate and extend the findings on our clinic-based sample. ${ }^{16}$

This study was undertaken as part of a larger cultural study of perceived communication preferences for receiving a cancer diagnosis, perceived causation of cancer, and terminologies for cancer among clinic and community-based samples ${ }^{17}$ and on lay beliefs about inheritance and kinship in the context of hereditary cancer among a sample of participants ascertained through two familial cancer services. ${ }^{16}$ In this article, we are reporting our findings on inheritance and kinship in the context of hereditary cancer among a community-based sample to validate findings in the clinic-based sample. Informed by the empirically derived findings from both the clinic- and community-based samples, we will then discuss strategies for cultural competence in cancer genetic counseling with Chinese families.

\section{MATERIALS AND METHODS}

The ethnographic methodology used has been described in detail in our previously published article. ${ }^{17}$ Purposive sampling (i.e., targeted sampling for heterogeneity to allow the determination of the full range of beliefs and explanations from as many different perspectives as possible) was used to select potential participants. ${ }^{18}$ We used a "participant observer" approach by first building up a personal relationship with potential participants, ${ }^{19}$ based on acceptance and trust that included participation in various activities conducted by the Chinese-Australian community. During this networking, discussion took place that provided general views on the issues under investigation. Fifteen community members also agreed to one or more private interviews with S.S.Y. to further explore the issues. Interviewing was discontinued once informational redundancy was reached. ${ }^{18}$

Most of the interviews were conducted in the informants' homes, in Cantonese, Hokkien, Mandarin, or English, according to the participant's preference. Interviews were tape-recorded if consent was given and lasted from 1 to 3 hours. Most of the encounters were held informally, covering several sessions over 2 to 6 days, with notes taken by the interviewer. An interview guide was used to structure the narrative, outlining the major topics to be covered, while leaving the wording and sequencing of questions open. ${ }^{16}$ The topics included sociodemographic and cultural background; family history of illness, including cancer; perceived communication preferences for receiving a cancer diagnosis; perceived causation of cancer; terminologies for cancer and causes of cancer; beliefs about inheritance of illnesses generally and cancer in particular; causation of hereditary cancer in families; concepts of kinship; and definitions of blood relatives and concepts of being "at risk" for a hereditary illness such as cancer. The narrative was structured in part by an adaptation of an Explanatory Model Schedule that was originally developed by one of the authors (M.E.) in English and in Khmer according to the Murdock Ethnographic Atlas. ${ }^{16}$ The instrument was translated into Mandarin and Cantonese, with successive piloting and testing of Cantonese 
and Mandarin terms, and adaptation of the trigger situation to illnesses such as cancer.

The Rissel Acculturation Scale ${ }^{20}$ was used as a measure of English language preference and proficiency and a proxy measure of acculturation. ${ }^{17}$ Data on language preference and proficiency and acculturation were used for descriptive purposes and to provide the basis for comparisons and contrasts undertaken as part of data analyses. The Rissel Acculturation Scale was used as an estimate of English language preference and proficiency. ${ }^{20}$ This eight-item scale has demonstrated high internal consistency and criterion-related validity in a sample of 851 Sydney general practice patients. Although the Rissel Acculturation Scale was developed to measure the degree of acculturation, it is, however, based on the traditional linear theory that assumes that as people adapt and acculturate to their new cultural surroundings, they necessarily strip off their old culture. Acculturation is, however, a complex and multidimensional construct, and the present study used the scale as an estimate of language preference and proficiency. Scores range from 0 to 35. Informants were categorized into those with low and high English language proficiency using a median split. Informants were categorized into those with low and high English language proficiency on the basis of their Rissel Acculturation Scale scores to enable comparisons of beliefs and attitudes between those with different levels of acculturation.

Detailed synopses were prepared for each informant, summarizing each account as a narrative in English. Several followups by the interviewer occurred to clarify or expand on some of the topics. The interview synopses were coded by S.S.Y. Data analyses were iterative, and K. B-S., S.S.Y., B.M., and M.E. participated in this process, using the synopses to identify and agree on emergent themes. In addition, conceptually clustered matrices, a form of visual display described by Miles and Huberman, ${ }^{21}$ were used to facilitate analysis both within and across cases. These tables cross-tabulated emergent themes by level of acculturation and were examined by S.S.Y., K. B-S., and B.M. to identify potential differences. Informant feedback to check and validate the findings was sought throughout the period of data collection. Ethics approval was obtained from three institutional ethics committees.

\section{RESULTS}

Sociodemographic and cultural background data, and details on family history of disease are shown in Table 1. Fifteen informants were included, 4 male and 11 female informants whose age ranged from the mid-20s to the mid-80s. Only three informants had some degree of a family history of cancer. There were lower educational levels and a higher proportion of Buddhists/Taoists in the community sample, compared with our clinic-based sample. ${ }^{17}$ Although they all identified as Chinese-Australian, informants were born in Hong Kong, China, Malaysia, Singapore, Indonesia, and Australia, illustrating the heterogeneity of the sample. The distribution of religious beliefs was also representative of Australian-Chinese population. All informants have been given a fictitious Chinese name when quoting them in the text to protect privacy and provide anonymity.

The majority of the informants centered their lives in the Chinese community. During the community networking and the individual interviews, S.S.Y. noted that often when discussing traditional beliefs, the term "superstitions" was used to describe these views, and many were careful not to seem "superstitious," regardless of their acculturations scores. For example, Ms. Zhang, who had a high acculturation score, noted that "the Chinese people are not as superstitious as before," and the same views were expressed by Ms. Xio who had a low acculturation score but described herself as a "modern woman."

\section{Patrilineal concept of kinship}

The concept of kinship reported by the majority of informants was strongly influenced by the notion of patrilineal descent. Informants reported that first cousins on the paternal side share the same surname and that all with the same surname are considered sisters and brothers. It was also noted that this included cousins as defined by the Anglo-Celtic notion of bilateral descent. As a consequence of this patrilineal notion of descent, maternal relatives might not be considered "close" relatives.

The dominance of the paternal line is illustrated by the fact that sons have a special place in the family. Ms. Chu said that when a relative dies "the oldest son (tall ngaei-hokkien) carries the hia law-hokkien (vessel [urn] containing the sticks of incense-joss-sticks)." Several informants also described this dominance as influencing perceptions of closeness of relatives, reporting that the Chinese usually considered the male family members and male descendants as higher ranking compared with the females. Females were often viewed as "belonging to another family," regardless of whether they were married or single. A woman who married into another family was considered as belonging to her husband's family, and her own family was said to have lost a daughter. This meant that the married daughter was perceived to be an addition to her husband's family but a loss to her own family. If the daughter remained single, she was still perceived as a potential loss because she would eventually marry and will then belong to her husband's household.

A common theme reported by the informants regardless of their religious beliefs, age, gender, or length of stay in Australia was that traditionally, the males were considered to be more likely to pass down general traits and illnesses to the future generations because they were higher in rank and were dominant in the society. It was often commented that if, for example, a child had good features or was intelligent, or even had a bad temper, he or she had inherited the father's zhung (an originally Buddhist term of karmic causality that ordinarily means seed), ${ }^{22}$ particularly if the father shared these traits. Males were considered the dominant authority in the Chinese family, and therefore they were regarded as the dominant force in passing down illnesses (Mr. Huang). If any female was perceived to be bringing misfortune to the family, she would be 
Table 1

Sociodemographic and acculturation characteristics of sample $(\mathrm{N}=15)$

\begin{tabular}{|c|c|c|c|c|c|c|c|c|c|}
\hline Pseudonym & Gender & Age & $\begin{array}{l}\text { Country of } \\
\text { birth }\end{array}$ & $\begin{array}{l}\text { Years since } \\
\text { migration }\end{array}$ & $\begin{array}{c}\text { Religious } \\
\text { background }\end{array}$ & $\begin{array}{l}\text { Language used } \\
\text { in interview }\end{array}$ & $\begin{array}{c}\text { Presence of family history of } \\
\text { illness }\end{array}$ & $\begin{array}{c}\text { Acculturation } \\
\text { level }^{a}\end{array}$ & $\begin{array}{l}\text { Language } \\
\text { proficiency }\end{array}$ \\
\hline Chan & $\mathrm{F}$ & Mid-50s & Indonesia & 13 & Catholic & Cantonese & $\begin{array}{l}\text { "Sporadic" diabetes, high } \\
\text { blood pressure, cancer }\end{array}$ & High & $\begin{array}{l}\text { English } \\
\text { Cantonese }\end{array}$ \\
\hline Zhang & F & Early $50 \mathrm{~s}$ & Hong Kong & 22 & Atheist & Cantonese & $\begin{array}{l}\text { Kidney failure, liver cancer, } \\
\text { gastric problems }\end{array}$ & High & $\begin{array}{l}\text { Cantonese, } \\
\text { English }\end{array}$ \\
\hline Xio & F & Mid-40s & Hong Kong & 2 & Catholic & Cantonese & $\begin{array}{l}\text { Diabetes, abdominal problems, } \\
\text { kidney, high blood pressure }\end{array}$ & Low & Cantonese \\
\hline Liang & $\mathrm{F}$ & Mid-30s & Hong Kong & 1 & Atheist & Cantonese & $\begin{array}{l}\text { Cancer dense (leukemia, liver } \\
\text { cancer), high blood pressure }\end{array}$ & Low & Cantonese \\
\hline Ting & $\mathrm{F}$ & Mid-20s & China & 4 & Atheist & Cantonese & $\begin{array}{l}\text { Cancer dense, lung, throat, } \\
\text { Alzheimer disease, tumors }\end{array}$ & High & $\begin{array}{l}\text { Cantonese, } \\
\text { English }\end{array}$ \\
\hline Goh & M & Mid-50s & Singapore & 45 & Atheist & $\begin{array}{l}\text { English, } \\
\text { Cantonese }\end{array}$ & $\begin{array}{l}\text { High blood pressure, heart } \\
\text { attacks, high cholesterol, } \\
\text { epilepsy }\end{array}$ & High & $\begin{array}{l}\text { English, } \\
\text { Cantonese }\end{array}$ \\
\hline Lai & M & Mid-40s & Malaysia & 12 & Christian & $\begin{array}{l}\text { English, } \\
\text { Cantonese }\end{array}$ & $\begin{array}{l}\text { Collapsed lung, high } \\
\text { cholesterol, gout }\end{array}$ & High & $\begin{array}{l}\text { English, } \\
\text { Cantonese }\end{array}$ \\
\hline Chu & $\mathrm{F}$ & Early 70s & Malaysia & 6 & $\begin{array}{l}\text { Christian } \\
\text { Anglican }\end{array}$ & $\begin{array}{l}\text { Hokkien, } \\
\text { English, } \\
\text { Malay }\end{array}$ & $\begin{array}{l}\text { Heart problems, diabetes, } \\
\text { cancer }\end{array}$ & Low & $\begin{array}{l}\text { Hokkien, } \\
\text { Malay, } \\
\text { English }\end{array}$ \\
\hline Tan & F & Mid-70s & Malaysia & 17 & $\begin{array}{l}\text { Christian } \\
\text { Presbyterian }\end{array}$ & $\begin{array}{l}\text { English, } \\
\text { Hokkien }\end{array}$ & $\begin{array}{l}\text { Heart problems, Parkinson } \\
\text { disease }\end{array}$ & High & $\begin{array}{l}\text { English, } \\
\text { Hokkien }\end{array}$ \\
\hline Ma & M & Late $60 \mathrm{~s}$ & China & 13 & Taoism & Cantonese & Diabetes, high blood pressure & Low & Cantonese \\
\hline Teo & F & Early 80 s & Hong Kong & 23 & Buddhist & Cantonese & $\begin{array}{l}\text { Diabetes, high blood pressure, } \\
\text { stomach problems }\end{array}$ & Low & Cantonese \\
\hline Huang & M & Mid-70s & China & 11 & Buddhist & Mandarin & $\begin{array}{l}\text { Gall bladder, heart problems, } \\
\text { lung cancer, partial deafness }\end{array}$ & Low & Mandarin \\
\hline $\mathrm{Li}$ & $\mathrm{F}$ & Late $40 \mathrm{~s}$ & Malaysia & 6 & Buddhist & $\begin{array}{l}\text { Hokkien, } \\
\text { Mandarin }\end{array}$ & $\begin{array}{l}\text { Fibroids, skin problems, } \\
\text { digestive, cancer }\end{array}$ & Low & $\begin{array}{l}\text { Hokkien, } \\
\text { Mandarin }\end{array}$ \\
\hline Lee & $\mathrm{F}$ & Early $50 \mathrm{~s}$ & China & 20 & Buddhist/Taoist & Cantonese & Asthma, liver cancer & Low & Cantonese \\
\hline $\mathrm{Wu}$ & $\mathrm{F}$ & Mid-80s & China & 17 & Buddhist/Taoist & Cantonese & Asthma, Parkinson disease & Low & Cantonese \\
\hline
\end{tabular}

${ }^{a}$ As assessed by the Rissel Acculturation Scale.

${ }^{b}$ As judged by the interviewer (S.S.Y.).

cast out of the family. Therefore, the belief was that this reduced the opportunity for women to transmit their illnesses to the younger generation.

\section{A weakness in the line}

The view was expressed that the presence of an illness in a generation indicated a weakness in the line (Ms. Liang). This weakness in a specific generation might predispose the following generations to the illness. The weakness might be in the physical form, such as a kidney problem, and may be the result of some evil deeds done by their ancestors that adversely affect the family fortune.

Several informants reported that when a marriage was planned, three generations of the family would be "checked" by the family of the woman to determine whether there is a weakness in the line, and yet this checking was usually done on the male side only, that is, the self, father, and grandfather. "In the olden days and even at present in Hong Kong, char san toi (checking the three generations) prior to a marriage agreement for ma fung (leprosy), fai (low-tuberculosis), or gu chiam (cancer) is done." (Mr. Ma)

Mr. Ma also said that the family of the man who is getting married would check the woman, her father, and her father's father's illnesses. This is because it was believed that males were "genetically stronger and the bloodline is greatest there, as traditionally Chinese males carry the family line and pass it down to other generations: char naim bien (mainly check the male side) [is done] as it is a common belief that males can inherit property and can also inherit illnesses and can pass down to future generations."

\section{Definitions of blood relatives and marriage between relatives}

The dominance of the paternal line was also described as impacting the way paternal and maternal cousins were perceived compared with how they are viewed where there is a bilateral notion of descent. "Chinese people will not approve of marriages to the father's brother's children (cousins) as these cousins are considered sisters and brothers (ah zhee, ah hia- 
hokkien). But the mother's brother's children (distant cousins) do not share the same surnames, are not considered close, and are allowed to marry." (Ms. Chu)

The narrative analyses showed that close kinship ties as defined by the various informants with different religious beliefs, gender, and age reflected the patrilineal kinship pattern in the Chinese society. Nevertheless blood relatives were distinguished from "extended" relatives such as the in-laws or spouses.

The majority of informants were consistent in reporting closeness as defined by the same bloodline. For example, Ms. Ting explained that those who share the same family name and have the same ancestors would be considered close relatives. They shared the same bloodline, and it was usually the male side of the family that would be considered close family. Ms. Ting elaborated that paternal uncles and aunts were included as close kin. Informants with a close linkage to the Chinese community reported that having a common ancestor defined membership of the family. However, there were also instances in which closeness could be defined by a different bloodline. It was reported that when there is no male heir, some Chinese families may adopt a son-in-law as a son and request that he change his surname: He would then be considered a blood relative (Ms. Chu). She also said that this practice was nevertheless uncommon given the disrespect that changing a surname would mean to his family.

Several informants defined family closeness in terms of their availability and frequency of contact, rather than bloodline (Ms. Chan and Ms. Liang). For example, they would include their own parents, husband, and children in their family history, but the frequency of contact would determine which of their sisters, brothers, aunts, and uncles would also be included.

\section{Beliefs about hereditary cancer}

Many Chinese participants expressed surprise that research had found that mutations in certain genes predisposed to breast or ovarian cancer and that these cancers can be hereditary. Most of them had little understanding of the implications that the identified genes could be traced to a specific member of the family.

From informal discussions that S.S.Y. had while networking in the community, it was clear that the younger informants, regardless of educational level, had a better understanding that cancer could be inherited, and many believed that cancer could be passed on through the genes. Many had obtained their information through the bilingual Chinese educators' health programs, media, and readings. In contrast, the elderly/older informants seemed to be uncertain and unclear whether cancer can be passed down through genes. They seemed less knowledgeable about the scientific findings and often relied on their friends or relatives for medical information. However, most also said that their family members, particularly senior members, would not accept that cancer could be transmitted through generations and was more likely the result of bad luck, fate, or some evil deed committed by an ancestor. One elderly informant stated that because males are considered the dominant authority in a Chinese family, he could be the dominant force in passing down the illness even if he was a grandfather passing the cancer onto a grandchild (Mr. Huang).

Another elderly informant said that her daughter-in-law told her that cancer could be passed down from parents to children, but she was uncertain because she knew of friends with no history of cancer who contracted cancer and died of it (Ms. Chu). This view was reinforced by the fact that cancer was not common in previous generations, and so it is seen as a "new disease." Ms. Zhang expressed the disbelief that it could have been passed down over many generations when it was previously virtually unknown.

The view that cancer could also be passed from a nonblood relative was also expressed in one case in which a spouse was viewed as the source of cancer that was transmitted through the blood (Ms. Teo). Her eldest brother believed that his mother's breast cancer was "caught" from their father because his father had a boil that had "no head" on his nipple for several years. Subsequently, their mother decided to suck the "boil" to try to reduce the swelling, at the same time sucking out the "head" (lun tau) and the pus. Her brother believed that their mother could have taken in some of the pus, which gave her the cancer.

\section{Interest in attending a familial cancer service}

Several informants described Chinese families as being reluctant to openly discuss or communicate about cancer within the family. Ms. Chu said that to have a fatal disease like cancer was shameful and considered a taboo topic in her family. She also reported that Chinese families avoided talking about illness because it was thought to bring bad luck to the family and was considered inauspicious, and several other informants described situations in which a diagnosis of cancer had been kept a secret within the family.

There was little awareness of the concept of genetic susceptibility to cancer among the community informants and, indeed, lack of acceptance of the concept, but the majority of informants said they would attend familial cancer services if it were suggested by their doctor. Three informants (Ms. Chu, Ms. Tan, and Ms. Wu), however, stated firmly that they would not attend. They were all elderly, but although Ms. Chu and Ms. Wu had low acculturation scores, Ms. Tan's score was high. The common factor was that their lives centered on the Chinese community, and there was continual reinforcement of their traditional beliefs within their family and social circles. The reasons they gave for not attending included a belief that it would only increase anxiety and lack of trust in the accuracy of a prediction, talking about cancer would make it "happen," and that if fated to have cancer then nothing could be done about it.

\section{DISCUSSION}

The clinic-based sample (those with a family history of cancer) espoused Western biomedical views that they may have 
picked up in the clinic, but folk beliefs were either held simultaneously by themselves or at least attributed to their senior relatives. ${ }^{17}$ The community informants, none of whom reported a family history of cancer, confirmed the folk beliefs reportedly held by the senior relatives of the clinic informants. ${ }^{16}$ Although the younger of these community informants reflected that they had heard through community activities and the media that cancer could be passed on through the genes, folk beliefs were also espoused. Indeed, although these traditional beliefs were often described as "superstitions," they were still widespread. All informants also believed that the dominance of the paternal line influenced reporting and perceptions of closeness of relatives. Relatives on the paternal side such as cousins were seen as sisters and brothers because they share the same surname. Likewise, maternal relatives may not be considered "close" relatives.

An examination of beliefs about genetic counseling and beliefs about cultural issues should be key components of culturally competent or multicultural genetic counseling services. ${ }^{4}$ The findings confirm observations with the clinic-based sample that it is important not to stereotype and make assumptions that folk beliefs are held on the basis of their level of acculturation or age. ${ }^{16}$ Similarly no relationship between health beliefs about breast cancer and acculturation in American-Chinese women has been observed. ${ }^{23}$ Discussions regarding their level of involvement and linkage with their community may be a better guide to their belief systems, but the most important strategy may be to simply ask patients what they believe after validating that people have a range of belief systems and to be nonjudgmental.

Even when the person being counseled does not hold folk beliefs, it may be that other family members do hold them. Discord may exist between the need for family involvement in a mutation search and cultural reluctance to discuss cancer with senior family members. The difference in beliefs and reluctance to believe what has been told in the clinic as reported by a number of informants can impact on the conduit of information within the family. ${ }^{16}$

\section{Suggested strategies for culturally competent communication with Chinese families}

Since the publication of our systematic review in $2001,{ }^{8}$ there have been further calls for research into the beliefs about cancer causation held by Chinese-Americans that may impact on cancer service use. ${ }^{24}$ Others have urged that genetic counseling practice in multicultural societies needs to avoid homogenized group stereotyping without attention to intragroup variation and individual differences. The value of drawing on direct experience of the community and the professionals involved has also been emphasized. ${ }^{4,25-27}$ Indeed, there is a growing body of empirical findings on culture-specific attitudes to genetic risk assessment and testing among African-Americans and to a lesser extent among Latinos and Ashkenazi-Jewish people. ${ }^{28-30}$ Our work is perhaps unique in its focus on an Asian community and provides empirically derived data on which to base recommendations for strategies genetic counseling staff may want to use to achieve culturally competent communication with Chinese families.

Our previous work and the findings reported here provide a rich source of knowledge about family dynamics and behaviors not easily gained using other methodologies. ${ }^{16,17,27}$ On the basis of these empirical findings, we have formulated specific suggestions to optimize the genetic counseling process with Chinese families to achieve culturally competent genetic counseling.

\section{Conveying the concept of mutation and the importance of language}

We previously described the view that the terms such as "mutation" and "faulty gene" had the potential to damage family honor when used without discussion and clarification. ${ }^{16}$ One of our clinic-based informants suggested that the association of having a faulty gene with family shame and a perception of a "weakness" in the line needed to be addressed by emphasizing early in the sessions that we are all born with several faulty genes. ${ }^{16}$ Our community-based informants confirmed these perceptions, explaining that the context of the term was the important issue rather than the term itself. These documented beliefs suggest that it may be beneficial to emphasize that faulty genes are not necessarily detrimental, and that some changes in a gene that make it faulty can confer benefits. An example that could be used is that being a carrier of the faulty gene for thalassemia protects people from malariaspreading mosquitoes. These documented beliefs also highlight the importance of avoiding language that perpetuates stigma associated with genetic disorders, for example, "Each family has its share of illness. What illnesses occur in your family?"

\section{Genetic counseling and genetic testing}

Our findings suggest that involvement of senior family members in the counseling session may be necessary, given the central role of the family in decision-making culture but recognizing that discord may exist between beliefs within the family. Several informants proposed that the genetic counseling team first ask what they or their family members believed was causing the cancer in the family. ${ }^{16}$ These findings suggest that it may be beneficial to discuss the family beliefs to enable the genetic counseling team to suggest ways of talking about the information with senior family members.

It is important to explain that the inheritance of a faulty gene can be a contributor to cancer in families in whom it occurs over a number of generations, and that it is possible to test for the faulty gene. However, another three clinic-based informants suggested that the genetic tests could also be expressed as checking the zhung of the person. ${ }^{16}$ This suggested strategy has recently been validated, in that it has been successfully implemented in a genetic counseling session by one of the authors of this article (K.T.).

The case was an Australian-Chinese lady who had clinical evidence of a likely hereditary nonpolyposis colorectal cancerrelated mutation (two cancers that had tumor evidence of a mismatch repair dysfunction). Her son had requested that she 
participate in genetic testing to determine whether the cancer in the family was the result of an inherited predisposition. $\mathrm{He}$ wanted to know whether he carried the mutation, because he would need annual colonoscopies if he did and none if he did not. Although she was initially reluctant to even discuss the possibility of a genetic predisposition despite a strong family history, the clinician involved used the strategy of discussing the beliefs of other Chinese people that cancer may be caused by bad luck as a means of opening up her concerns about testing. The clinician involved pointed out that everyone had approximately 30,000 genes, and that it was normal that a few of these would be faulty so that they were not working as they should. She equated the test to being a way to determine whether her son had inherited the bad luck and needed to have colonoscopies, or whether he had not inherited the bad luck and thus could avoid the need for the procedures. She was then happy to have the test. The mutation was identified, and the son was able to have predictive testing. Her husband was of the firm belief that a colonoscopy had caused the cancer in his wife and would also cause cancer in his son.

Traditional Chinese medicine approaches illness and its treatment from a holistic perspective. ${ }^{31}$ When illness occurs, the total body is seen as being disturbed and warranting treatment of the diseased body, not just the particular organ. In the Chinese world view, it could be that the genes are seen as part of the body and as being part of the imbalance between ying and yang. If the Chinese use the term "bad genes," it often includes the concepts of morality and good character of their predecessors or parents, but they seldom use the term solely in the biomedical term. Genes (yun zi) are a reasonably new concept, because in the traditional Chinese medicine there is no such thing as genes. Compatibility with their innate beliefs may therefore be achieved by a discussion of checking for a sign of bad luck, the zhung or the imbalance that exists between the ying and yang, rather than checking for a "faulty gene."

\section{Cancer risk is sometimes inherited}

The Western belief is that some illnesses can be inherited, and a risk for cancer is one of them. This can be likened to thinking that some people may have inherited changes in their zhung, and that these changes may increase the risk for cancer.

\section{Benefits of genetic testing}

Our findings suggest that it may be helpful to explain that early detection of cancer may save lives, and that the genetics team is working toward helping patients, their children, and their families by identifying those family members at increased risk. For example, suggesting that "although there is no guarantee that your children will not have cancer, you have done something for them by participating in the testing," may be beneficial.

\section{Disadvantages of genetic testing}

Our findings also suggest that the identification of a "weakness in the line" may impact on marriage prospects. In addition, among our clinic-based sample, we observed an elderly informant who was reluctant to have blood drawn for genetic testing, because she believed that blood could not be replaced (unpublished data, 2002). It is important for practitioners and genetic counselors to be aware of such culture-based beliefs, which will need to be acknowledged and addressed as sensitively as possible. The involvement of family members with cancer is often essential for mutation searching. In some cases these people may not have been told that they have cancer, and the family may not want such disclosure to occur. Again, these difficulties may be overcome if the test is equated to a test of their zhung, or testing for the first sign of bad luck or the imbalance between their ying and yang, rather than for a search for the faulty gene causing their cancer or predisposition to cancer in the family.

\section{Eliciting family health history}

Even though there was a greater level of importance associated with the paternal line, all informants believed that relatives on both mother's and father's side should be included in a discussion of family history. Definitions of "close" relatives will vary strongly between cultures. In Chinese culture, for example, maternal relatives may not be considered "close" relatives. Practitioners should ask the questions about health problems for each side of the family separately, rather than asking about close relatives, for example, "tell me about your mother's sister and brother and their children" (Western term for "first cousins").

When taking a family history the issue of consanguinity may need to be explored sensitively. Although marriage between first cousins on the paternal side would not be approved, there would be acceptance of marriage between first cousins on the maternal side, simply because these relatives would traditionally not be perceived as close blood relatives and described as "distant cousins." Therefore consanguineous relationships may be in the family tree but would not necessarily be perceived as such if on the maternal side. There has recently been an international focus on the importance of documenting family health history. ${ }^{32}$ The findings from this study that a patient's notion of descent can impact how they report kinship are important for the development of family history tools. Indeed the Centre for Genetics Education of the New South Wales Genetics Service, based in Sydney, Australia, has recently revised their family history guide for consumers and professionals so that directions are provided to ensure that each "side" of the family is separately ascertained..$^{33,34}$

\section{Toward cultural competence}

The experience and needs of minority ethnic populations are perhaps not all that different from the general population, but at the same time effective policy and practice must also understand and address differences when they do emerge. ${ }^{35}$ Minority groups in Australia, as in many other countries such as the United States, constitute a significant and growing percentage of the population, and the need for cultural competence in health service provision to assist in reducing health disparities such as access to cancer genetic counseling services 
is increasingly recognized. ${ }^{5-8,36}$ Although one barrier to lack of use of services is a lack of awareness of the services, increased awareness alone will not ensure that access increases and more effort is needed to overcome identified barriers such as providing culturally appropriate services and tailored educational materials. ${ }^{37,38}$

The findings and our experience suggest that the communication process with the patients may be enhanced if the counselor can learn about the family's beliefs and culture by first establishing a sense of trust and maintaining a nonjudgmental attitude so as not to dismiss a patient's beliefs. Because family communication underpins discourse within the family about genetic risk, ${ }^{39}$ the findings also suggest that recognition of the family role in decision-making used by Chinese-Australians and other culturally and linguistically diverse groups ${ }^{40}$ will be important in fostering family communication.

There are several key limitations of this work. First, it remains focused on the cultural attributions of the patients as "other," in the sense of their differences from the dominant culture. Second it does not factor in the cultural reflections by the staff of the services, and further work is needed to examine the interplay between the cultural diversity of the patients and the staff. Third, the findings suggest that medical practitioners, genetics teams, and other health professionals may be more effective in their communication with Chinese-Australian patients by incorporating the patient's and their family's belief systems in describing cancer genetic testing and taking care with terminology. However, further research is required to determine whether the use of the suggested strategies in genetic counseling with this group would lead to improved outcomes and then its wider applicability in other cultures.

\section{ACKNOWLEDGMENTS}

The project was supported by grants from the Women's Health Service, and Multicultural Health Unit, South East Sydney Area Health Service, and has been supported by The Cancer Council of New South Wales. Soo See Yeo was seconded for part of the project to the Center for Culture and Health from the New South Wales Department of Community Services. Bettina Meiser is supported by Public Health Australia Fellowship 007079 from the National Health and Medical Research Council of Australia. We are most grateful to the informants for sharing this information so generously. We are grateful to the organizations who assisted with access to and recruitment of community informants: the New South Wales Chinese Community Workers Network; the Hills Women's Association; the Australian Chinese Community Association; Hurstville Community Health Centre; Auburn Community Health Services; Blacktown Community Health Services; St. George Chinese Workers' Network; and Western Sydney Chinese Workers Network.

\section{References}

1. Wonderling D, Hopwood P, Cull A, Douglas F et al. A descriptive study of UK cancer genetic services: an emerging response to the new genetics. Br J Cancer 2001; 85(2):166-170
2. Risch H, McLaughlin J, Cole D, Rosen B et al. Prevalence and penetrance of germline BRCA1 and BRCA2 mutations in a population series of 649 women with ovarian cancer. Am J Hum Genet 2001;68:700-710.

3. Eisenbruch M. The lens of culture, the lens of health: toward a framework and toolkit for cultural competence. Resource document, for UNESCO Asia-Pacific Regional Training Workshop on Cultural Mapping and Cultural Diversity Programming Lens to Safeguard Tangible and Intangible Cultural Expressions and Protect Cultural Diversity. Bangkok: 2004:1-248.

4. Lewis LJ. Models of genetic counseling and their effects on multicultural genetic counseling. J Genet Couns 2002;11(3):193-212.

5. Genao I, Bussey-Jones J, Brady D, Branch WT Jr. et al. Building the case for cultural competence. Am J Med Sci 2003;326(3):136-140.

6. The National Center for Cultural Competence. Cultural Competency Fact Sheet Georgetown University Center for Child and Human Development. http://www.dml. georgetown.edu.au/depts/pediatrics/gucdc 2003. Accessed December 10, 2005.

7. The Center for Culture and Health. http://cch.med.unsw.edu.au/cch.nsf/website/ education. Sydney: University of NSW, 2005. Accessed December 10, 2005.

8. Meiser B, Eisenbruch M, Barlow K, Tucker K et al. Cultural aspects of cancer genetics: setting a research agenda. J Med Genet 2001;38:425-429.

9. Wang V, Marsh FH. Ethical principles and cultural integrity in health care delivery: Asian ethnocultural perspectives in genetic services. J Genet Couns 1992;1(1):81-92.

10. National Breast Cancer Centre. Current Best Advice About Familial Aspects of Breast/ Ovarian Cancer. Sydney: NHMRC National Breast Cancer Centre, 2000.

11. Australian Cancer Network. Guidelines on Familial Aspects of Cancer. Sydney: Australian Cancer Network, 1999.

12. Eisinger F, Alby N, Bremond A, Dauplat J et al. Recommendations for medical management of hereditary breast and ovarian cancer: The French National Ad Hoc Committee. Ann Oncol 1998;9:939-950.

13. Burke W, Daly M, Garber J, Botkin J et al, for the Cancer Genetics Studies Consortium. Recommendations for follow-up care of individuals with an inherited predisposition to cancer. II. BRCA1 and BRCA2. JAMA 1997;277(12):997-1003.

14. Burke W, Petersen G, Lynch P. Recommendations for follow-up care of individuals with an inherited predisposition to cancer. I. Hereditary non-polyposis colorectal cancer. JAMA 1997;277(11):915-919.

15. Australian Cancer Network. Familial Aspects of Bowel Cancer: A Guide for Health Professionals. 2002: http://www.cancer.org.au/documents/Familial\%20 aspects\%20 of \%20bowel \%20cancer.pdf. Accessed December 10, 2005.

16. Eisenbruch M, Yeo S, Meiser B, Goldstein D et al. Optimizing clinical practice in cancer genetics with cultural competence: Lessons to be learned from ethnographic research with Chinese-Australians. Soc Sci Med 2004;59(2):235-248.

17. Yeo SS, Meiser B, Barlow-Stewart K, Goldstein D et al. Understanding community beliefs of Chinese-Australians about cancer: Initial insights using an ethnographic approach. Psychooncology 2005;14:174-186.

18. Patton M. Qualitative Evaluation and Research Method. 2nd ed. London: Sage, 1990

19. Spradley J. The Ethnographic Interview. New York: Holt, Rinehart \& Winston, 1979.

20. Rissel C, Lesjak M, Ward J. Cardiovascular risk factors among Arabic-speaking patients attending Arabic-speaking general practitioners in Sydney. Ethn Health 1998;3(3):213-222.

21. Miles MB, Huberman AM. Qualitative Data Analysis: An Expanded Sourcebook. 2nd ed. London: Sage, 1994.

22. Walter A. Getting an Heir. Honolulu, HI: University of Hawaii Press, 1990.

23. Chen W, Bakken S. Breast cancer knowledge assessment in female Chinese immigrants in New York. Cancer Nurs 2004;27(5):407-412.

24. Wong-Kim E, Sun A, DeMattos MC. Assessing cancer beliefs in a Chinese immigrant community. Cancer Control 2003;10(5 Suppl):22-28.

25. Weil J. Multicultural education and genetic counseling. Clin Genet 2001;59(3):143149 .

26. Wang VO. Multicultural genetic counseling: then, now, and in the 21 st century. Am J Med Genet 2001;106(3):208-215.

27. Peters J, McAllister C, Rubenstein W. Qualitative cancer genetic counselling research, part I: ethnography in a cancer clinic. J Genet Couns 2001;10(2):133-149.

28. Thompson H, Valdimarsdottir H, Duteau-Buck C, Guevarra J et al. Psychosocial predictors of BRCA counseling and testing decisions among urban African-American women. Cancer Epidemiol Biomakers Prev 2002;11:1579-1585.

29. Singer E, Antonucci T, Van Hoewyk J. Racial and ethnic variations in knowledge and attitudes about genetic testing. Genet Test 2004;8(1):31-43.

30. Phillips KA, Warner E, Meschino WE, Hunter J et al. Perceptions of Ashkenazi Jewish breast cancer patients on genetic testing for mutations in BRCA1 and BRCA2. Clin Genet 2000;57:376-383.

31. Ming Z. The Medical Classic of the Yellow Emperor. First ed. Beijing: Foreign Language Press, 2001: ISBU: 711902664X

32. U.S Surgeon General's Family History Initiative. United States Department of Health and Human Services, 2004: http://www.hhs.gov/familyhistory/. Accessed December 10, 2005. 


\section{Barlow-Stewart et al.}

33. Barlow-Stewart K. The Importance of the Family Health Tree: A Guide for Professional Use. Sydney: The Centre for Genetics Education, 2003: http://www.genetics.com.au/ publications/fhtprof.htm. Accessed December 10, 2005.

34. Barlow-Stewart K. The Importance of Your Family Health Information. Sydney: The Centre for Genetics Education, 2003: http://www.genetics.com.au/publications/fhtcons.htm. Accessed December 10, 2005.

35. Atkin K. Ethnicity and the politics of the new genetics: principles and engagement. Ethn Health 2003;8(2):91-109.

36. Glanz K. Correlates of intentions to obtain genetic counseling and colorectal cancer gene testing among at-risk relatives from three ethnic groups. Cancer Epidemiol Biomarkers Prev 1999;8:329-336.
37. Baty BJ, Kinney AY, Ellis SM. Developing culturally sensitive cancer genetics communication aids for African Americans. Am J Med Genet 2003;118A(2):146155 .

38. Honda K. Who gets the information about genetic testing for cancer risk? The role of race/ethnicity, immigration status, and primary care clinicians. Clin Genet 2003;64 (2):131-136.

39. Forrest K, Simpson SA, Wilson BJ, van Teijlingen ER et al. To tell or not to tell: barriers and facilitators in family communication about genetic risk. Clin Genet 2003;64(4):317-326.

40. Leung K. The role of beliefs in Chinese culture. In: The Handbook of Chinese Psy chology. Bond MH (Ed.) 1996:247-262. 